\title{
A bacosides containing Bacopa monnieri extract alleviates allodynia and hyperalgesia in the chronic constriction injury model of neuropathic pain in rats
}

\author{
Muhammad Shahid ${ }^{1,2^{*}}$, Fazal Subhan ${ }^{1 *}$ (D) Nisar Ahmad ${ }^{1}$ and Ihsan Ullah ${ }^{3}$
}

\begin{abstract}
Background: The current therapy of neuropathic pain is inadequate and is limited by the extent of pain relief and the occurrence of dose dependant side effects. Insufficient control of pain with conventional medications prompts the use of complementary and alternative medicine therapies by patients with neuropathic pain. This study therefore investigated a standardized methanolic extract of Bacopa monnieri, a widely reputed nootropic plant, for prospective antinociceptive effect in the chronic constriction injury (CCl) model of neuropathic pain.

Methods: Placement of four loose ligatures around the sciatic nerve produced partial denervation of the hindpaw in rats. Bacopa monnieri (40 and $80 \mathrm{mg} / \mathrm{kg}$, p.o) and the positive control, gabapentin (75 mg/kg, i.p), were administered daily after $\mathrm{CCl}$ or sham surgery and the behavioral paradigms of static- and dynamic-allodynia (paw withdrawal threshold to von Frey filament stimulation [PWT] and paw withdrawal latency to light-brushing [PWL]), cold-allodynia (paw withdrawal duration [PWD] to acetone), heat- (PWL to heat-stimulus) and punctate-hyperalgesia (PWD to pin-prick) were assessed on days 3, 7, 14 and 21.
\end{abstract}

Results: CCl consistently generated static- (days 3-21), dynamic- (days 14-21) and cold-allodynia (days 3-21) plus heat- and mechano-hyperalgesia (days 3-21). The tested doses of Bacopa monnieri significantly attenuated the CClinduced allodynia and hyperalgesia, exemplified by increased PWT (days 7-21), PWL to light brushing (days 14-21) and heat (days 7-21) as well as decreased PWD to pin prick and cold stimuli (days 3-21). The extract also counterbalanced the $\mathrm{CCl}$-induced aberrations in the nociceptive behaviors by increasing the pain threshold to that of pre-surgery baseline. Gabapentin also afforded analogous beneficial behavioral profile but of higher magnitude.

Conclusions: Our findings suggest that Bacopa monnieri can be used as adjuvant therapy for neuropathic pain conditions afflicted with allodynia and hyperalgesia.

Keywords: Bacopa monnieri, Bacoside-A, Rat model of neuropathy, Nociception, Pain paradigms

\section{Background}

Neuropathic pain refers to pain that originates from pathology of the nervous system. Its symptoms include spontaneous and stimulus evoked painful sensations manifested as paraesthesia, paroxysmal pain, hyperalgesia (pain sensation is significantly enhanced) or allodynia

\footnotetext{
* Correspondence: shahidsalim_2002@hotmail.com; fazal_subhan@upesh.edu.pk

'Department of Pharmacy, University of Peshawar, Peshawar, Khyber Pakhtunkhwa 25120, Pakistan

Full list of author information is available at the end of the article
}

(non-noxious stimuli cause pain) [1]. Neuropathic pain is a disease of global burden. Despite rapid development of neuroscience and modern techniques related to drug discovery, effective drugs to mitigate the symptoms of neuropathic pain are still lacking. A plethora of randomized controlled trials have demonstrated potential effectiveness of gabapentinoids, tricyclic antidepressants and opioids; however, these pain ameliorating medications are inadequate and their effectiveness is limited by the extent of pain relief provided and the occurrence of significant side effects [2]. 
Complementary and alternative medicine therapies are regularly used by patients with chronic neurological disorders including neuropathic pain. The most common reason for their usage is insufficient control of pain with conventional medications [3]. Among a large number of plant derived remedies, Bacopa monnieri (Linn.) Pennell [family: Scrophulariaceae] has been considered as a reputable nootropic medicine and is traditionally used for memory enhancing, rejuvenating, increasing longevity and promoting progeny [4]. Experimental studies have shown that Bacopa monnieri possesses anti-dementia [5], cognitive enhancing [6, 7], antidepressant [8], anti-anxiety [9], antiepileptic [10-12], antiparkinson [13, 14], antiamnesic [15-17], antibacterial [18], antidiabetic [19], anti-inflammatory [20-22], anti-arthritis [23], antihypertensive [24], anticancer [25], anti-asthmatic [26], spasmolytic [27], antiulcer [28, 29], analgesic [30-32], anti-aging [33], antifungal [34], antioxidant [35-37], adaptogenic [38, 39], anti-addictive [40, 41], lessened narcotics-induced toxicity [42], neuroprotective [35, 43-45], antiemetic [46, 47], cardioprotective [48, 49], hepatoprotective [50-53] and nephroprotective [53, 54] properties. Clinical trials have shown that Bacopa monnieri has both acute $[55,56]$ and chronic [55-59] cognitive enhancing effects and improves memory performance in older persons $[60,61]$ and patients with Alzheimer's disease [62]. The major chemical constituents isolated from Bacopa monnieri are dammarane type triterpenoid saponins with jujubogenin and pseudojujubogenin as the aglycones including bacosides $A_{1}-A_{3}$, bacopasaponins $A-G$ and bacopasides I-V $[63,64]$. Bacoside-A along with bacopaside-I constituted more than $96 \% \mathrm{w} / \mathrm{w}$ of the total saponins of Bacopa monnieri [65].

Bacopa monnieri has shown its utility against tonic visceral chemically-induced nociceptive pain and acute phasic thermal nociception in animal studies [66]. Additionally, Bacopa monnieri attenuates opioid tolerance, enhances opiates-induced analgesia and has morphine like analgesic effect without producing any tolerance to its own analgesic effect $[66,67]$. However, there is little evidence of its efficacy in attenuating neuropathic pain conditions. A previous study in rats shows that Bacopa monnieri is an effective analgesic in a model of diabetic neuropathy as it allays streptozotocin-induced hyperalgesia and the protection has been afforded via stimulation of adenosine $\mathrm{A}_{1}$-receptors [68]. In this study we further corroborated the effectiveness of Bacopa monnieri against neuropathic pain in a well characterized rat model of chronic sciatic nerve constriction injury using the well known behavioral testing paradigms of allodynia and hyperalgesia.

\section{Methods}

\section{Drugs and chemicals}

Gabapentin (supplied by Lowitt Pharmaceuticals, Peshawar, Pakistan), HPLC grade acetonitrile and methanol (Sigma-Aldrich, St. Louis, USA), HPLC standards of bacoside- $\mathrm{A}_{3}$, bacopaside-II and bacopasaponin-C (gifted by Prof. Dr. Ikhlas Khan, National Center for Natural Products Research, School of Pharmacy, The University of Mississippi, Mississippi, USA), xylazine (Xylaz ${ }^{\circ}$, $20 \mathrm{mg} / \mathrm{mL}$, Bladel, Netherlands) and ketamine (Ketarol ${ }^{\circ}$, $50 \mathrm{mg} / \mathrm{mL}$, Global Pharmaceuticals, Islamabad, Pakistan).

\section{Preparation of Bacopa monnieri extract}

Naturally grown Bacopa monnieri was collected in April from a stream near Margalla hills, Islamabad, Pakistan. After authentication by Prof. Dr. Mohammad Ibrar (Pharmacognosist; Department of Botany, University of Peshawar), a specimen was deposited in the herbarium with a voucher number 20016 (PUP). The aerial parts were separated, shade dried and coarsely grinded. The powdered material was treated with $n$-hexane and further treated with acetone to remove chlorophyll type pigments. It was subjected to extraction with methanol in a Soxhlet apparatus. The obtained extract was then filtered and concentrated in a rotary evaporator under reduced pressure at $50{ }^{\circ} \mathrm{C}$. It was finally dried on a water bath to obtain a semisolid mass (yield, 6.5\%).

\section{HPLC quantification of bacosides in Bacopa monnieri}

Bacopa monnieri was quantified for bacoside "A" major components including bacoside- $\mathrm{A}_{3}$, bacopaside-II and bacopasaponin- $C$ by a previously described validated high performance liquid chromatography (HPLC) method [66]. The HPLC system consisted of double pumps (LC-20AT Shimadzu, Japan) with UV detector (SPD-20A Shimadzu, Japan) and column (Purospher C18, $250 \mathrm{~mm} \times 4.6 \mathrm{~mm} \times 4 \mu \mathrm{m}$ particle size). Briefly, $5 \mathrm{mg}$ of Bacopa monnieri extract was mixed with $5 \mathrm{~mL}$ of HPLC grade methanol, centrifuged for $10 \mathrm{~min}$ at $3000 \mathrm{rpm}$, filtered through a $0.45 \mu \mathrm{m}$ filter and the filtered solution was then injected into the HPLC system. Mobile phase was prepared by mixing $0.2 \%$ phosphoric acid and acetonitrile $(62: 38 \mathrm{v} / \mathrm{v})$, sonicated for $15 \mathrm{~min}$ and filtered under vacuum through a $0.45 \mu \mathrm{m}$ filter paper. With the system flow rate set at $0.6 \mathrm{~mL} / \mathrm{min}$ and the wavelength of the detector at $205 \mathrm{~nm}$, all the peaks in Bacopa monnieri extract were obtained within a runtime of 33 min. The peaks in Bacopa monnieri extract were confirmed by spiking the standards with samples.

\section{Animals}

Male Sprague-Dawley rats, weighing 300-450 g were used. They were maintained in a $12 \mathrm{~h}$ light/dark cycle at $22 \pm 2{ }^{\circ} \mathrm{C}$ throughout the study duration with ad libitum 
access to food and water. All experimental procedures on animals were approved by the Ethical Committee (13/EC-15/Pharm) of the Department of Pharmacy, University of Peshawar, which were in accordance with the UK Animals (Scientific Procedures) Act 1986 and conformed to the ARRIVE guidelines for the reporting of in vivo experiments.

\section{Induction of neuropathic nociception in rats}

The chronic constriction injury (CCI) model, which is based on a partial denervation of the sciatic nerve as described by Bennett and Xie [69] was used for induction of neuropathic nociception. The animals were anesthetized with an intraperitoneal injection of a mixture of xylazine $(10 \mathrm{mg} / \mathrm{kg})$ and ketamine $(100 \mathrm{mg} / \mathrm{kg})$. With proper surgical care, four loose ligatures were tied with a double knot, $1 \mathrm{~mm}$ apart and proximal to the trifurcation of the sciatic nerve. The constriction of nerve was minimal and was immediately stopped until a brief twitch was observed. An identical operation was performed, except that the sciatic nerve was not ligated in the sham-operated animals [70].

\section{Treatment groups}

All drugs were dissolved in normal saline. Bacopa monnieri extract was orally administered daily in doses of 40 and $80 \mathrm{mg} / \mathrm{kg}$ [71, 72]. Gabapentin, used as a positive control, was intraperitoneally administered once daily at a dose of $75 \mathrm{mg} / \mathrm{kg}$ [73]. All animals were randomly divided into the following groups $(n=6$ animals per group) and the study was continued for 21 days.

\section{Group 1: Sham-operated control}

Group 2: Chronic constriction injury (CCI) control

Group 3: CCI + gabapentin $(75 \mathrm{mg} / \mathrm{kg} /$ day, i.p)

Group 4: CCI + Bacopa monnieri extract $(40 \mathrm{mg} / \mathrm{kg} /$ day,

p.o)

Group 5: CCI + Bacopa monnieri extract $(80 \mathrm{mg} / \mathrm{kg} /$ day,

p.o)

Group 6: Sham-operated + gabapentin $(75 \mathrm{mg} / \mathrm{kg} /$ day,

i.p)

Group 7: Sham-operated + Bacopa monnieri extract

( $40 \mathrm{mg} / \mathrm{kg} /$ day, p.o)

Group 8: Sham-operated + Bacopa monnieri extract

(80 mg/kg/day, p.o)

\section{Neuropathic nociception testing paradigms}

The behavioral testing paradigms of allodynia and hyperalgesia were used to assess neuropathic nociception. The animals were transferred to a specially designed elevated wire mesh bottom table. They were acclimatized for $\sim 20 \mathrm{~min}$ and subsequently tested for static and dynamic allodynia, heat hyperalgesia, mechanical hyperalgesia and cold allodynia on -3 (pre-surgery) and postsurgically on days $3,7,14$ and 21 .

\section{Static allodynia}

The up and down method as reported by Chaplan et al. [74] was used for the assessment of static allodynia. The mid-plantar surface of the operated left hindpaw was subjected to a series of 8 von Frey filaments $(0.4,0.70$, $1.20,2.00,3.63,5.50,8.50$, and $15.10 \mathrm{~g}$ ) (Stoelting USA). Each hair was applied perpendicularly until it buckled. A period of $6 \mathrm{~s}$ was selected as a cut-off time or until a positive response occurred (withdrawal of paw). The pattern of each response was converted to the $50 \%$ withdrawal threshold (PWT, g).

\section{Dynamic allodynia}

The mid-plantar surface of the operated left hindpaw was lightly stroked with a cotton bud. The time taken to show a withdrawal reaction (lifting or licking the paw) was considered as the paw withdrawal latency (PWL). A cut-off time of $15 \mathrm{~s}$ was selected [75].

\section{Heat hyperalgesia}

A heated plate maintained at a constant temperature $\left(56{ }^{\circ} \mathrm{C}\right)$ was touched slightly with the mid-plantar surface of the operated left hindpaw. The heat source was adjusted at the beginning of the experiment to yield a paw flick in $\sim 10 \mathrm{~s}$. The paw withdrawal latency (PWL) was recorded, with a minimal value of $0.5 \mathrm{~s}$ and a maximum of $10 \mathrm{~s}$ [76].

\section{Punctate hyperlagesia}

The tip of an ordinary safety pin was pressed against the skin of the mid-plantar surface of the operated left hindpaw such that the skin was dimpled but not penetrated. The duration of paw withdrawal (PWD) was recorded, with an arbitrary minimal time of $0.5 \mathrm{~s}$ (for the brief normal response) and a maximal cut-off of $15 \mathrm{~s}$ [77].

\section{Cold allodynia}

The mid-plantar surface of the operated left hindpaw was delicately sprayed with $50 \mu \mathrm{L}$ of acetone using a needle connected to a syringe. The duration of the withdrawal response (PWD) was recorded with an arbitrary minimal value of $0.5 \mathrm{~s}$ and a maximum of 15 s [77].

\section{Statistical analysis}

Data were expressed as mean \pm S.E.M. The final data were analyzed using two-way repeated measures analysis of variance (ANOVA) followed by post hoc Bonferroni test. Student's t test was used for statistical significance between pre-surgical and post-surgical response data. All statistical analyses were conducted using GraphPad Prism 5 (GraphPad Software Inc. San Diego CA, USA). A $P$ value of $\leq 0.05$ was accepted as significant. 


\section{Results}

Standardization of Bacopa monnieri methanolic extract The HPLC-UV analysis of the Bacopa monnieri methanolic extract confirmed the presence of bacoside- $\mathrm{A}_{3}$, bacopaside-II and bacopasaponin- $\mathrm{C}$ in quantities of $31.62 \mu \mathrm{g} / \mathrm{mg}, 5.41 \mu \mathrm{g} / \mathrm{mg}$ and $1.01 \mu \mathrm{g} / \mathrm{mg}$ respectively (Fig. 1). The chromatographic analysis showed that bacoside- $\mathrm{A}_{3}$ was the major component of bacoside- $\mathrm{A}$ in the Bacopa monnieri extract. The total quantity of bacoside "A" three-major components was revealed as $38.04 \mu \mathrm{g} / \mathrm{mg}$ of extract.

\section{Effect of Bacopa monnieri on mechanical allodynia Effect of Bacopa monnieri on static mechano-allodynia} A significant decrease $(P<0.001)$ in the nociceptive threshold to the innocuous mechanical von Frey hairs (static allodynia) was produced in the operated left hindpaw after unilateral sciatic nerve ligation, when observed on days 3-21 as compared to the sham-operated animals. Additionally, the unilateral ligation caused a significant reduction in PWT, prominent on day 3 $(5.037 \pm 0.7251 \mathrm{~g}, P<0.01)$, day $7(2.262 \pm 0.3148 \mathrm{~g}$, $P<0.001)$, day $14(1.872 \pm 0.3543 \mathrm{~g}, P<0.001)$ and day $21(1.538 \pm 0.5192 \mathrm{~g}, P<0.001)$ compared to their presurgery baseline values (14.42 $\pm 0.9910 \mathrm{~g})$.

The treatments have significant main dose effect on the CCI-induced static allodynia [time $=(F(4175)=22.79$, $P<0.0001)$, treatment $=(F(7175)=48.34, P<0.0001)$, interaction $=(F(28,175)=3.24, P<0.0001)]$. Daily administration of Bacopa monnieri in doses of 40 and $80 \mathrm{mg} / \mathrm{kg}$ alleviated the evoked nociception to normally non-painful gentle static pressure stimuli on the hindpaw mid-plantar surface by significantly restoring $(P<0.01, P<0.001)$ the CCI-induced decrease in PWT, noticed on days 3 (only for
$80 \mathrm{mg} / \mathrm{kg}$ ), 7, 14 and 21 post-ligation. The PWT values for the $40 \mathrm{mg} / \mathrm{kg}$ dose on day $3(8.215 \pm 1.445 \mathrm{~g}, P<0.01)$, day 7 (7.237 $\pm 0.4558 \mathrm{~g}, P<0.001)$, day $14(8.138 \pm 1.011 \mathrm{~g}$, $P<0.01)$ and day $21(8.557 \pm 1.583 \mathrm{~g}, P<0.01)$ approached the pre-surgery baseline values $(15.00 \mathrm{~g})$. Similarly, the $80 \mathrm{mg} / \mathrm{kg}$ dose also afforded a highly efficient protective effect as the post-surgery PWT values on days 3 (9.682 $\pm 1.393 \mathrm{~g}, P<0.05), 7$ (11.85 $\pm 1.501 \mathrm{~g}), 14$ $(10.55 \pm 1.413 \mathrm{~g}, P<0.05)$ and $21(11.46 \pm 1.357 \mathrm{~g}$, $P<0.05)$ drew close to pre-ligation PWT of $15.00 \mathrm{~g}$.

The daily $75 \mathrm{mg} / \mathrm{kg}$ dose of the positive control, gabapentin produced a robust static anti-allodynic effect by significantly relieving $(P<0.01, P<0.001)$ the neuropathic nociception evoked by application of von Frey hairs to the mid-plantar surface of the operated left hindpaw compared to the untreated CCI control group. The static anti-allodynic effect was also evidenced by a less significant difference in PWT from pre-surgery value of $15.47 \pm 0.4683 \mathrm{~g}$ (day -3 ) to post-surgery values of $10.26 \pm 1.714 \mathrm{~g}($ day $3, P<0.05), 9.737 \pm 2.213 \mathrm{~g}$ (day 7$)$, $10.72 \pm 1.290 \mathrm{~g}$ (day $14, P<0.01)$ and $10.11 \pm 1.659 \mathrm{~g}$ (day $21, P<0.05$ ).

No static allodynia was observed in the sham-operated control or sham plus Bacopa monnieri/gabapentin treated animals at any time during the 30 days of observation (Fig. 2).

\section{Effect of Bacopa monnieri on dynamic mechano-allodynia}

In comparison to the sham-operated animals, the dynamic allodynia in the CCI-operated animals took a slow course to develop and was observable on day 14 when a brisk reduction $(P<0.001)$ in the latency to withdraw the operated left hindpaw was produced after lightly stroking the mid-plantar region with a cotton bud. The

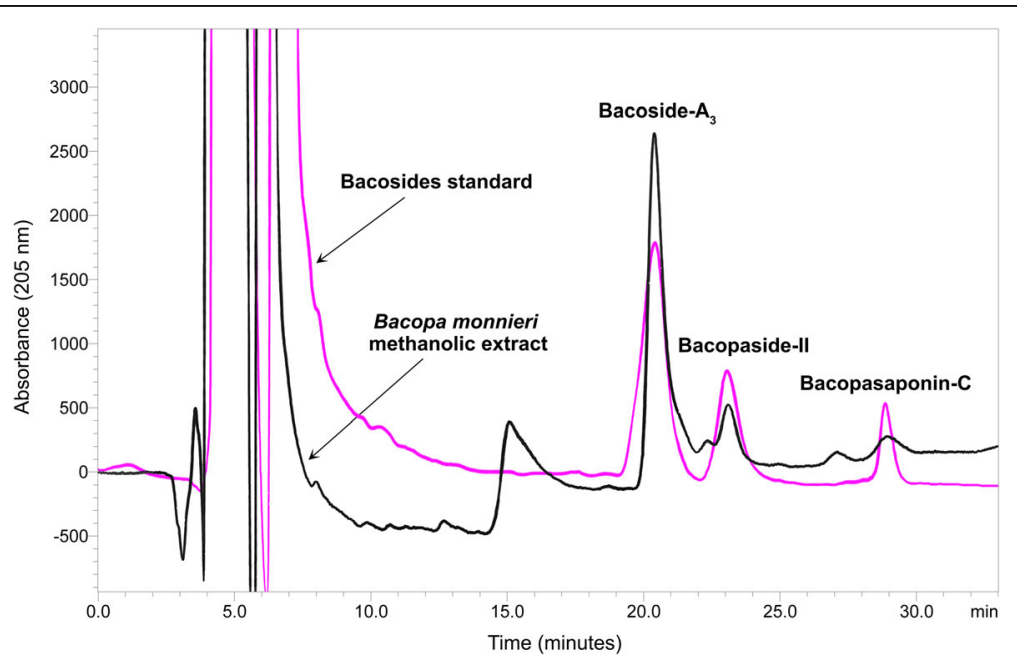

Fig. 1 HPLC-UV fingerprint of bacoside "A" major components (bacoside- $A_{3}$, bacopaside-II and bacopasaponin-C) quantified in Bacopa monnieri methanolic extract overlaid with that of standard bacosides 


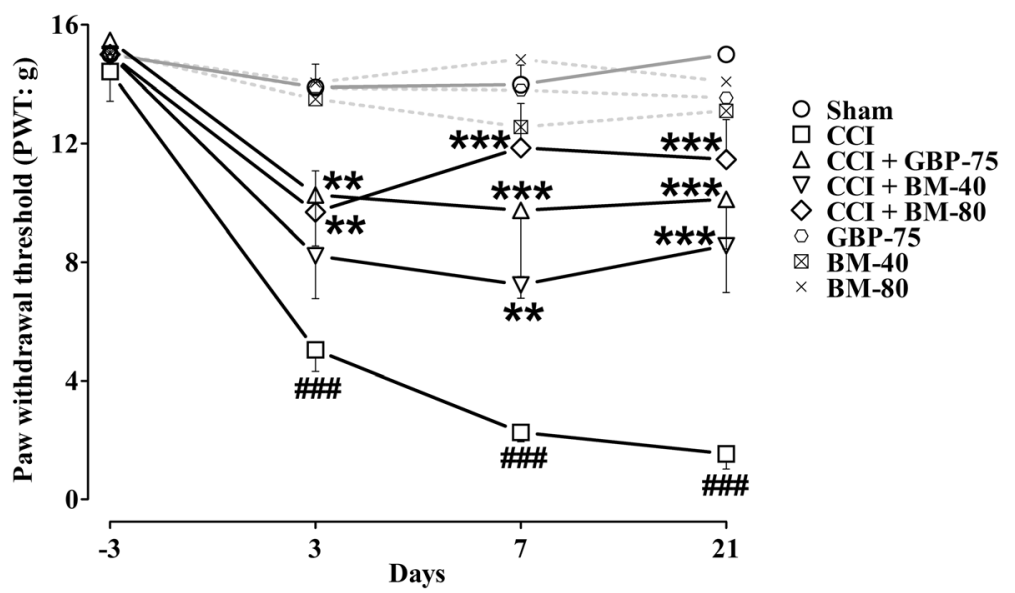

Fig. 2 Effect of Bacopa monnieri methanolic extract (BM-40 and BM-80) and gabapentin (GBP-75) on the maintenance of chronic constriction injury (CCI) induced static allodynia (diminished von Frey filament threshold pressure; PWT in g). Values expressed as mean \pm S.E.M. \#\#\# $<0.001$ compared to sham-operated animals, ${ }^{* * P}<0.01,{ }^{* * *} P<0.001$ compared to CCl-operated untreated animals, two-way repeated measures ANOVA followed by post hoc Bonferroni analysis. $n=6$ rats per group

reduction in the PWL to normally non-painful lightpressure moving stimuli was noticeable for the subsequent week of study (day 21, $P<0.001$ ). Moreover, the PWL values also significantly changed from the presurgery baseline PWL values of $11.85 \pm 1.426 \mathrm{~s}$ to $3.110 \pm 0.4216 \mathrm{~s}(P<0.01)$ and $3.515 \pm 0.6215 \mathrm{~s}$ $(P<0.01)$ on days 14 and 21 , respectively.

Treatment with Bacopa monnieri and gabapentin significantly modified the CCI-induced dynamic allodynia [time $=(F(4175)=3.00, P<0.0378)$, treatment $=(F$ $(7175)=9.81, \quad P<0.0001)$, interaction $=(F$ $(28,175)=1.76, P<0.0152)]$. Bacopa monnieri treated animals (40 and $80 \mathrm{mg} / \mathrm{kg})$, significantly elevated $(P<0.01, P<0.001)$ the CCI-induced reduction in PWL on days 14 and 21 . The resistance against hyperresponsiveness to the innocuous stroking of cotton bud was also evident by a non-significant difference in the latency to lift the operated hindpaw on day 14 $(8.605 \pm 1.584 \mathrm{~s}$ and $12.91 \pm 1.327 \mathrm{~s})$ and day 21 $(11.93 \pm 1.451 \mathrm{~s}$ and $11.97 \pm 1.242 \mathrm{~s})$ compared to day $-3(12.60 \pm 1.636 \mathrm{~s}$ and $14.51 \pm 0.3392 \mathrm{~s})$, respectively at doses of 40 and $80 \mathrm{mg} / \mathrm{kg}$.

The daily systemic dose of the positive control, gabapentin $(75 \mathrm{mg} / \mathrm{kg})$ showed a dominant protective effect against CCI-induced evoked dynamic allodynia on days 14 and $21(P<0.001)$, which was further confirmed by elevation of post-surgery PWL on days 14 $(11.07 \pm 1.099 \mathrm{~s})$ and $21(12.02 \pm 1.161 \mathrm{~s})$ compared to that of pre-surgery value on day $-3(11.61 \pm 1.165 \mathrm{~s})$.

The sham-operated control as well as the per se treated Bacopa monnieri/gabapentin animals did not show any dynamic allodynia during the entire study duration (Fig. 3).

\section{Effect of Bacopa monnieri on heat hyperalgesia}

A significant exaggerated $(P<0.001)$ response to normally non-painful heat stimuli evoked nociception was observed post-surgically in the untreated CCI control animals as compared to the sham-operated animals during the entire study duration. The nociceptive thermal sensation in the mid-plantar area measured as reduced latency to paw withdrawal was significantly $(P<0.001)$ changed from pre-surgery baseline of $5.797 \pm 0.2119 \mathrm{~s}$ to $2.032 \pm 0.1028 \mathrm{~s}, 1.938 \pm 0.07910 \mathrm{~s}, 1.932 \pm 0.1795 \mathrm{~s}$ and $1.948 \pm 0.1477 \mathrm{~s}$ on days $3,7,14$ and 21, respectively.

Significant effect on the CCI-induced heat hyperalgesia [time $=(F(4175)=15.84, P<0.0001)$, treatment $=(F$ $(7175)=43.21, P<0.0001)$, interaction $=(F$ $(28,175)=2.92, P<0.0001)]$ was produced by Bacopa monnieri and gabapentin. Treatment with Bacopa monnieri at 40 and $80 \mathrm{mg} / \mathrm{kg}$ altered the CCI-induced exaggerated response by significantly elevating $(P<0.05$, $P<0.01)$ the PWL upon heat stimuli starting from day 7 till the end of study (day 21). Both the 40 and $80 \mathrm{mg} / \mathrm{kg}$ doses uplifted the post-surgical PWL on day 7 $(3.787 \pm 0.5617 \mathrm{~s}$ and $4.305 \pm 0.8559 \mathrm{~s})$, day 14 $(3.705 \pm 0.3627 \mathrm{~s}, P<0.05$ and $3.833 \pm 0.5276 \mathrm{~s}$, $P<0.05)$ and day $21(3.750 \pm 0.2884 \mathrm{~s}, P<0.05$ and $4.235 \pm 0.3723 \mathrm{~s}, P<0.01)$, respectively when compared to their pre-surgical PWL values $(5.838 \pm 0.5921 \mathrm{~s}$ and $6.767 \pm 0.5032 \mathrm{~s})$.

A highly efficient resistance $(P<0.05, P<0.01)$ to heat hyperalgesia was produced by a daily intraperitoneal dose of gabapentin $(75 \mathrm{mg} / \mathrm{kg})$ on days $3-21$ as compared to the CCI control group. The post-ligation threshold to perceive heat stimuli evoked nociception 


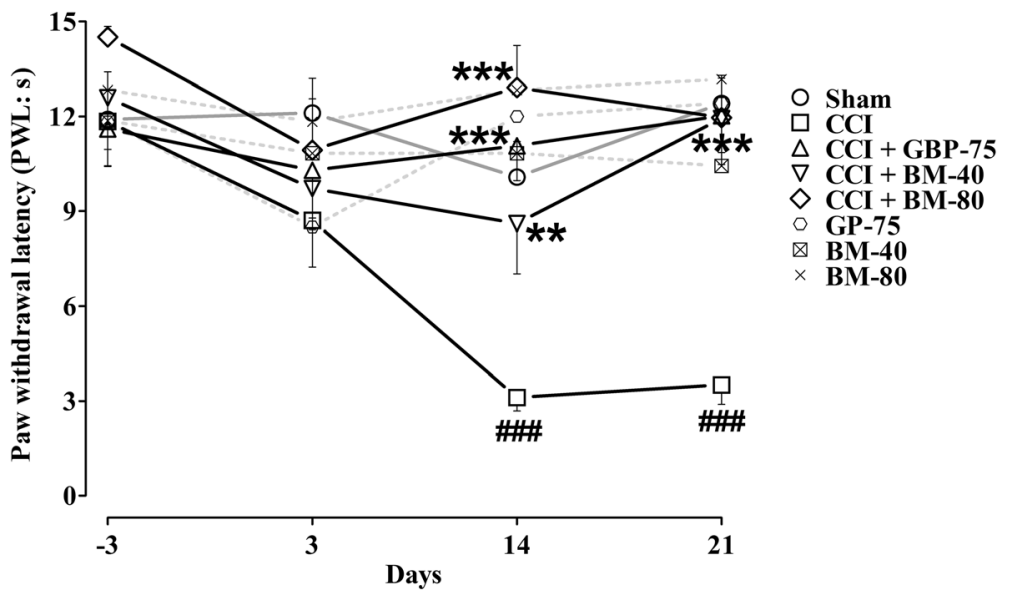

Fig. 3 Effect of Bacopa monnieri methanolic extract (BM-40 and BM-80) and gabapentin (GBP-75) on the maintenance of chronic constriction injury (CCI) induced dynamic allodynia (diminished paw withdrawal latency to light brushing; PWL in s). Values expressed as mean \pm S.E.M. ${ }^{\# \# \# P} P<0.001$ compared to sham-operated animals, ${ }^{* *} P<0.01$, ${ }^{* *} P<0.001$ compared to CCl-operated untreated animals, two-way repeated measures ANOVA followed by post hoc Bonferroni analysis. $n=6$ rats per group

was elated by gabapentin to $3.587 \pm 0.2387 \mathrm{~s}(P<0.05)$ (day 3), $3.910 \pm 0.3705$ s $(P<0.01)$ (day 7), $3.933 \pm 0.2500 \mathrm{~s}(P<0.01)$ (day 14) and $4.395 \pm 0.2487 \mathrm{~s}$ (day 21), compared to pre-ligation baseline of $5.770 \pm 0.3662 \mathrm{~s}($ day -3$)$.

The per se treatment with Bacopa monnnieri and gabapentin treated animals showed a robust antihyperalgesic effect $(P<0.001)$ throughout the experimental duration as compared to the $\mathrm{CCI}$ controls (Fig. 4).

\section{Effect of Bacopa monnieri on punctate hyperalgesia}

The unilateral sciatic nerve ligation produced an exaggerated response to a noxious stimuli evoked nociception manifested as a significant increase $(P<0.001)$ in PWD, which was prominent from day 3 up to day 21 . The hyperalgesia induced by manual pricking of the mid-plantar surface of the operated left hindpaw significantly raised $(P<0.01, P<0.001)$ the PWD from pre-surgery baseline of $0.5 \mathrm{~s}$ to $8.707 \pm 0.9516 \mathrm{~s}$ on day $3,10.37 \pm 1.760 \mathrm{~s}$ on day $7,8.278 \pm 1.598 \mathrm{~s}$ on day 14 and $8.995 \pm 0.6923 \mathrm{~s}$ on day 21 .

Analysis revealed significant main dose effect was afforded by Bacopa monnieri and gabapentin on the CCI-induced mechanical hyperalgesia [time $=(F$ $(4175)=23.93, \quad P<0.0001)$, treatment $=(F$ $(7175)=103.35, \quad P<0.0001)$, interaction $=(F$ $(28,175)=7.06, P<0.0001)]$. Treatment with Bacopa

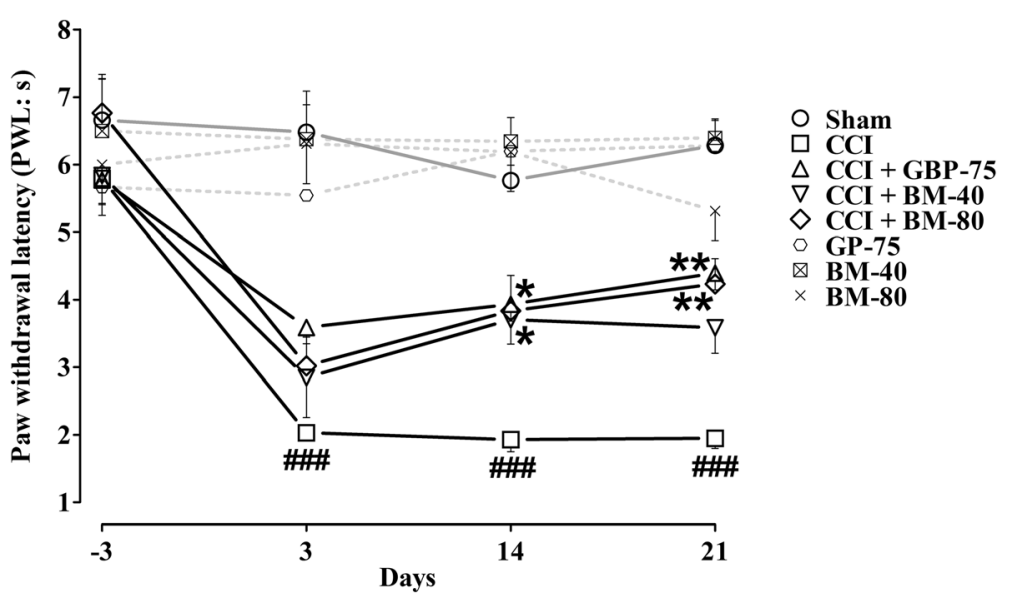

Fig. 4 Effect of Bacopa monnieri methanolic extract (BM-40 and BM-80) and gabapentin (GBP-75) on the maintenance of chronic constriction injury (CCI) induced heat hyperalgesia (shortened paw withdrawal latency to heat stimulus; PWL in s). Values expressed as mean \pm S.E.M. $\# \# P<0.001$ compared to sham-operated animals, $* P<0.05, * * P<0.01$ compared to CCl-operated untreated animals, two-way repeated measures ANOVA followed by post hoc Bonferroni analysis. $n=6$ rats per group 
monnieri extract significantly abolished $(P<0.001)$ the CCI-induced hyperalgesic response to the noxious pin prick at doses of 40 and $80 \mathrm{mg} / \mathrm{kg}$ during the entire treatment duration. The extract significantly counterbalanced $(P<0.05, P<0.01)$ the $\mathrm{CCI}$-induced increased PWD upon application of a noxious stimulus at 40 and $80 \mathrm{mg} / \mathrm{kg}$ on day $3 \quad(4.702 \pm 1.458 \mathrm{~s}$ and $3.060 \pm 0.4325 \mathrm{~s})$, day $7(2.985 \pm 0.3177 \mathrm{~s}$ and $3.038 \pm 0.6042 \mathrm{~s})$, day $14(2.925 \pm 0.4848 \mathrm{~s}$ and $2.790 \pm 0.3451 \mathrm{~s})$ and day $21(2.833 \pm 0.3955 \mathrm{~s}$ and $3.167 \pm 0.4609 \mathrm{~s})$ compared to their respective presurgery baseline PWD (0.5 s).

The hypersensitivity during the experimental period was also significantly lessened $(P<0.001)$ by the $75 \mathrm{mg} / \mathrm{kg}$ daily dose of gabapentin compared to the untreated CCI control group. Moreover, in comparison to the baseline $(0.5 \mathrm{~s}$, day -3$)$, the positive control also opposed the sharp pricking hyper-responsiveness when tested post-surgically for PWD on day $3(4.088 \pm 0.5006 \mathrm{~s}, P<0.001)$, day 7 $(3.955 \pm 0.2851 \mathrm{~s}, P<0.001)$, day $14(3.218 \pm 0.3680 \mathrm{~s}$, $P<0.001)$ and day $21(3.180 \pm 0.2998 \mathrm{~s}, P<0.001)$.

Significant $(P<0.001)$ alleviation of punctate hyperalgesia was demonstrated by the sham-operated plus Bacopa monnieri and gabapentin treated animals throughout the treatment period (Fig. 5).

\section{Effect of Bacopa monnieri on cold allodynia}

A significant exaggerated withdrawal reflex $(P<0.001)$ hastened upon application of a drop of acetone on the mid-plantar surface of the operated left hindpaw prompted by unilateral sciatic nerve ligation compared to that produced by sham-operation. The duration of paw lifting incited by the cooling effect of acetone was markedly increased $(P<0.001)$ to $9.948 \pm 1.200 \mathrm{~s}$,
$12.52 \pm 0.818 \mathrm{~s}, 12.23 \pm 0.784 \mathrm{~s}$ and $14.22 \pm 0.438 \mathrm{~s}$ on days $3,7,14$ and 21 , respectively from the pre-surgery baseline of $0.5 \mathrm{~s}$ (day -3$)$.

Bacopa monnieri and gabapentin have significant effect on the maintenance of CCI-induced cold allodynia [time $=(F(4175)=96.57, P<0.0001)$, treatment $=(F$ $(7175)=255.61, \quad P<0.0001)$, interaction $=(F$ $(28,175)=18.62, P<0.0001)]$. The normally non-painful cold stimuli evoked nociception initiated by the ligation procedure was significantly subsided $(P<0.001)$ by Bacopa monnieri in doses of 40 and $80 \mathrm{mg} / \mathrm{kg}$ for the entire study period. The increment in paw withdrawal duration after surgery was suppressed by $40 \mathrm{mg} / \mathrm{kg}$ to $6.567 \pm 1.149 \mathrm{~s}$ (day $3, P<0.01$ ), $5.040 \pm 0.5520 \mathrm{~s}$ (day 7 , $P<0.001$ ), $5.568 \pm 0.3626 \mathrm{~s}$ (day $14, P<0.001$ ) and $5.595 \pm 0.5726 \mathrm{~s}$ (day $21, P<0.001)$ when compared to pre-surgery value of $0.5 \mathrm{~s}$. Likewise, the decrement in PWD was also prominent for $80 \mathrm{mg} / \mathrm{kg}$ on day 3 $(3.008 \pm 0.1528 \mathrm{~s}, P<0.001)$, day $7(4.148 \pm 0.1946 \mathrm{~s}$, $P<0.001)$, day $14(5.380 \pm 0.5755 \mathrm{~s}, P<0.001)$ and day $21(5.918 \pm 1.013 \mathrm{~s}, P<0.01)$.

A robust increase $(P<0.001)$ in the threshold to perceive the acetone-induced nociceptive cold stimuli was demonstrated by the positive control, gabapentin when administered daily in a dose of $75 \mathrm{mg} / \mathrm{kg}$. The increase in nociceptive threshold was prominent when the post-surgical duration of paw withdrawal was compared to pre-surgery baseline of $0.5 \mathrm{~s}$ (day -3) and measured as $4.657 \pm 0.5292 \mathrm{~s}$ on day $3(P<0.001)$, $5.252 \pm 0.7290 \mathrm{~s}$ on day $7(P<0.01), 6.152 \pm 0.8892 \mathrm{~s}$ on day $14(P<0.01)$ and $3.870 \pm 0.6106 \mathrm{~s}$ on day 21 $(P<0.01)$.

The sham-operated plus Bacopa monniera/gabapentin treated animals significantly attenuated $(P<0.001)$ the

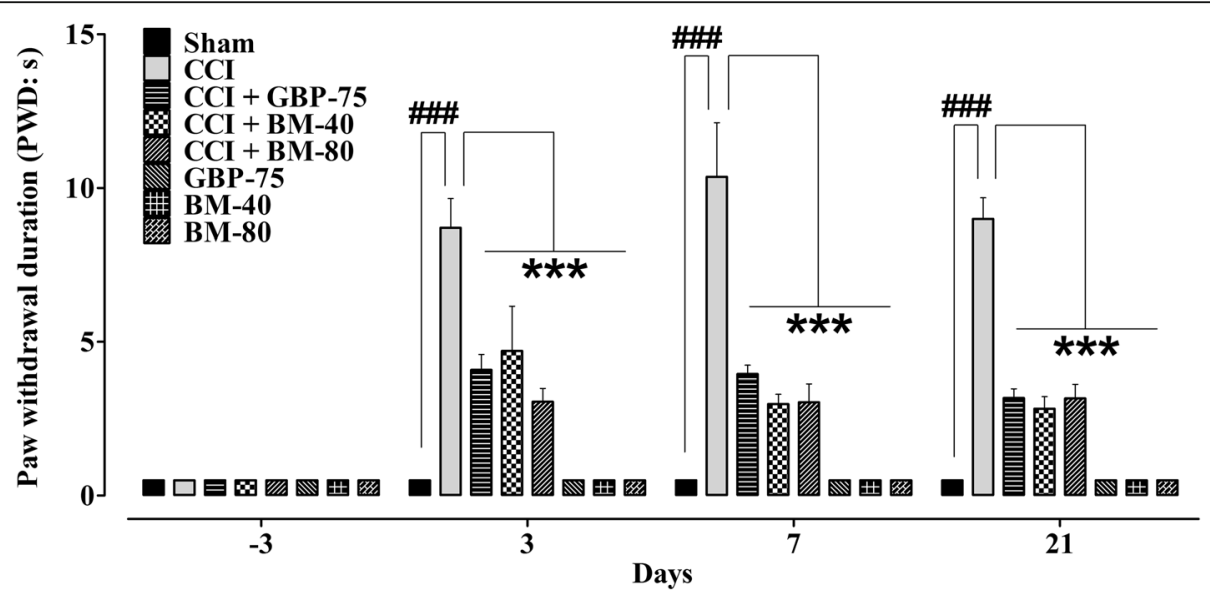

Fig. 5 Effect of Bacopa monnieri methanolic extract (BM-40 and BM-80) and gabapentin (GBP-75) on the maintenance of chronic constriction injury (CCI) induced punctate hyperalgesia (increased paw withdrawal duration to pin prick; PWD in s). Values expressed as mean \pm S.E.M. $\# \# P<0.001$ compared to sham-operated animals, ${ }^{* * *} P<0.001$ compared to CCl-operated untreated animals, two-way repeated measures ANOVA followed by post hoc Bonferroni analysis. $n=6$ rats per group 
acetone-evoked cold allodynia throughout the study period, compared to the CCI controls (Fig. 6).

\section{Discussion}

This study assessed the beneficial effect of Bacopa monnieri in the chronic constriction injury model of neuropathic pain under standardized experimental conditions. Animal models of peripheral nerve injury combined with testing of pain hypersensitivity are useful in representing human neuropathic pain syndromes [78]. Therefore, new drugs need be evaluated in these animal models before going into clinical trials for their utility in neuropathic pain. The chronic sciatic nerve constriction injury model mimics many of the pathophysiological properties of chronic neuropathic pain in human and has been demonstrated to be sensitive to a number of compounds which are used clinically for the symptomatic treatment of chronic neuropathic pain. In this study, the timecourse of development and the degree of mechanical allodynia and hyperalgesia in the employed CCI method was similar as previously reported elsewhere [79].

Chronic pain following peripheral or central nerve injury presents more difficult task as the drugs successfully used in an acute pain are usually inefficient for neuropathic pain. This study has demonstrated that treatment with Bacopa monnieri significantly suppressed the evoked nociceptive responses when orally administered daily in doses of 40 and $80 \mathrm{mg} / \mathrm{kg}$, which were tolerable and benign based on the toxicity profile $[31,80]$. Similar doses of Bacopa monnieri have been shown to possess significant neuroprotective effects including its ability to protect the cerebral cortex [81], enhance dendritic length and arborization of amygdala [71] and hippocampal $\mathrm{CA}_{3}$ neurons [72]. Moreover, these doses also have significant anti-stress and anti-depressant activities $[38,82]$ and neuropathic pain is often associated with comorbidities such as anxiety and depression, resulting in a low health-related quality of life [83].

In this study, we tested Bacopa monnieri against allodynia and hyperalgesia induced after a peripheral nerve injury. Allodynia and hyperalgesia are frequent symptoms of disease and may be useful adaptations to protect vulnerable tissues. Both may, however, also emerge as diseases in their own right [84]. A number of compounds have been used to modulate neuropathic allodynia, hyperalgesia and other manifestations of neuropathic pain [73, 85-87]. In this study, we clearly demonstrated that Bacopa monnieri succinctly inhibited the maintenance of static and dynamic allodynia, heat, punctate and cold allodynia in the rat model of CCIinduced neuropathic nociception. A previous study from the same laboratory showed that a hydroethanolic extract of Bacopa monnieri ( $80 \mathrm{mg} / \mathrm{kg}$, i.p) increased the hot-plate nociceptive response latency, in mice [88]. However, in this study, the tested doses of methanolic Bacopa monnieri extract have demonstrated no effect on the latency time in the sham-operated control rats. This discrepancy in the results might be due to differences in the paradigms concerning the sensitivity of response latency in the heat-nocifensive test adopted in this study (see Additional file 1) and that of the hot-plate test [89-91] as used previously in the same laboratory [88]. Additionally, the effect of variations in bacosides contents, present in the hydroethanolic and methanolic

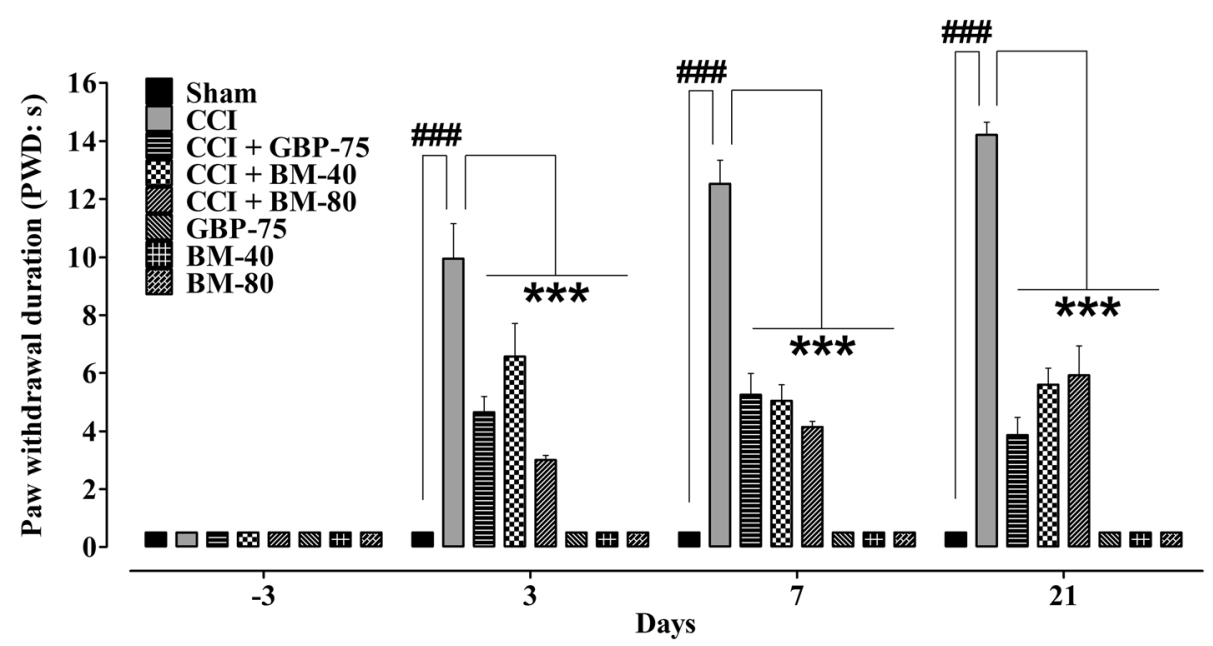

Fig. 6 Effect of Bacopa monnieri methanolic extract (BM-40 and BM-80) and gabapentin (GBP-75) on the maintenance of chronic constriction injury (CCI) induced cold allodynia (increased paw withdrawal duration to a drop of acetone; PWD in s). Values expressed as mean \pm S.E.M. $\# \# P<0.001$ compared to sham-operated animals, ${ }^{* * *} P<0.001$ compared to CCl-operated untreated animals, two-way repeated measures ANOVA followed by post hoc Bonferroni analysis. $n=6$ rats per group 
extracts cannot be ignored, as bacoside-A concentration varies between different solvents [46]. Moreover, a significant variation exists in the bacoside-A content of the various Bacopa monnieri accessions collected from different locations [64, 92].

The neuropathic nociception alleviating effect afforded by Bacopa monnieri was equipotent to the positive control, gabapentin which was daily administered in a dose of $75 \mathrm{mg} / \mathrm{kg}$ for 21 days. Gabapentin is currently recommended as first-line treatment for neuropathic pain and is effective at relieving allodynia and hyperalgesia not only in animal models, but also in numerous clinical trials in a wide variety of pain syndromes including diabetic neuropathy and postherpetic neuralgia [93-95]. However, its clinical effectiveness is limited to the magnitude of pain relieved and to the occurrence of dose-dependent side effects, of which dizziness, somnolence, ataxia and lethargy, being the most significant [93].

Neuropathic pain is the consequence of a complex interplay of mechanisms in the peripheral and central nervous system which include: 1) Sensitization of the nociceptor (increase bradykinin, prostaglandins, serotonin, substance P, NGF). 2) Abnormal ectopic excitability of afferent neurons and sympathetically maintained pain (voltage-gated sodium and calcium channels). 3) Disinhibition of nociception at the spinal inhibitory network (GABAergic, opioidergic and glycinergic receptors). 4) Pronociceptive facilitation at the spinal dorsal horn (glutaminergic receptors, TNF $\alpha$, NGF, microglia). 5) Supraspinal mechanisms (decrease in norepinephrine, serotonin, dopamine, endogenous opioids). Treatment based on the mechanism(s) of pain is widely accepted to be theoretically better than treatment based on the cause of pain [96]. Although, the mechanism through which Bacopa monnieri ameliorates allodynia and hyperalgesia is still unknown; nonetheless, in view of its myriad pharmacological profile it can be speculated that multiple mechanisms might be involved as Bacopa monnieri possesses anti-nociceptive activity [30] mediated through opioidergic mechanisms [88], enhances the morphine anti-nociceptive effects [66], increases synaptic plasticity [97], up-regulates vesicular glutamate transporter type 2 (VGLUT2) [98] and decreases the immunodensity of glutamate/ $N$-methyl-D- aspartate receptor subtype 1 (NMDAR1) [99]. What is more, Bacopa monnieri increases $\mathrm{GABA}, \mathrm{GABA}_{\mathrm{A}}$ receptor subunit, $\mathrm{GABA}_{\mathrm{A}}$ receptor binding and up-regulation of GAD gene [11]. Additionally, Bacopa monnieri decreases the release of TNF- $\alpha$ and IL-6 [22] and inhibits the activities of COX2, LOX-5 and LOX-15 [21]. Herbal medicines are reported to be beneficial in the management of painful neuropathy [100-102] and recently there has been a dramatic increase in the use of complementary and alternative medicine especially herbal therapies, to reduce pain [103-105].

\section{Conclusions}

In summary, this study demonstrates for the first time that a bacosides rich fraction of Bacopa monnieri presents marked antinociceptive properties by alleviating allodynia and hyperalgesia in the chronic constriction injury model of neuropathic pain in rats. Bacopa monnieri may constitute a beneficial herbal remedy for the efficient management of neuropathic pain syndromes. The antinociceptive effect of Bacopa monnieri against neuropathic pain requires further studies not only for elucidating the exact mechanism but also needs to be tested in other neuropathic pain models as there are differences between animal models in terms of the magnitude of each pain component. Additionally, the major bioactive constituent, bacoside-A should be tested in the $\mathrm{CCI}$ model, to validate its role in the neuropathic pain alleviating effect of Bacopa monnieri.

\section{Additional file}

Additional file 1: Effect of acute administration of Bacopa monnieri extract on heat-nocifensive response latency evoked by a heated probe maintained either at a constant temperature of $56{ }^{\circ} \mathrm{C}$ with a cut-off latency time of $10 \mathrm{~s}$ (Experiment S1) or at $50^{\circ} \mathrm{C}$ with a cut-off latency time of $60 \mathrm{~s}$ (Experiment S2) in normal rats. (DOCX $516 \mathrm{~kb}$ )

\section{Abbreviations}

BM: Bacopa monnieri methanolic extract; CCl: Chronic constriction injury; COX: Cyclooxygenase; GABA: Gamma amino butyric acid; GAD: Glutamic acid decarboxylase; GBP: Gabapentin; HPLC: High performance liquid chromatography; IL-6: Interleukin 6; LOX: Lipoxygenase; NGF: Nerve growth factor; NMDAR1: Glutamate/N-methyl-D- aspartate receptor subtype 1; PWD: Paw withdrawal duration; PWL: Paw withdrawal latency; PWT: Paw withdrawal threshold; TNFa: Tumor necrosis factor alpha; VGLUT2: Vesicular glutamate transporter

\section{Acknowledgements}

The authors are thankful to Professor Dr. Ikhlas Khan, the National Center for Natural Products Research, School of Pharmacy, The University of Mississippi, Mississippi, USA for the gift of HPLC standards of bacosides. The authors are also thankful to Lowitt Pharmaceuticals, Peshawar, Pakistan for the donation of gabapentin active material.

\section{Funding}

The authors have not received any funding for this study.

\section{Availability of data and materials}

All data that support the findings of this study are available from the corresponding authors upon reasonable request.

\section{Authors' contributions}

MS conducted the experiments and performed the analysis and interpretation of data. He also prepared the final version of manuscript. FS guided the research group as supervisor throughout the study. NA attributed necessary experimental materials and helped in the surgical procedure. IU assisted in the HPLC analytical work. All authors read and approved the final manuscript. 


\section{Consent for publication}

Not applicable.

\section{Ethics approval and consent to participate}

The experimental procedures on laboratory animals were approved by the Ethical Committee of the Department of Pharmacy, University of Peshawar, Pakistan (13/EC-15/Pharm) and were in accordance with the UK Animals (Scientific Procedures) Act 1986.

\section{Publisher's Note}

Springer Nature remains neutral with regard to jurisdictional claims in published maps and institutional affiliations.

\section{Author details}

'Department of Pharmacy, University of Peshawar, Peshawar, Khyber Pakhtunkhwa 25120, Pakistan. ${ }^{2}$ Department of Pharmacy, Sarhad University of Science and Information Technology, Peshawar, Pakistan. ${ }^{3}$ Department of Pharmacy, University of Swabi, Swabi, Pakistan.

\section{Received: 25 August 2016 Accepted: 26 May 2017}

\section{Published online: 05 June 2017}

\section{References}

1. IASP. Pain terms: a current list with definitions and notes on usage. Classification of Chronic Pain, 2nd edition, IASP Task Force on Taxonomy, eds H. Merskey, H., Bogduk, N. IASP Press, Washington DC; 1994. p. 209-14. updated 2014. http://www.iasp-pain.org.

2. Attal N. Pharmacologic treatment of neuropathic pain. Acta Neurol Belg. 2001;101(1):53-64.

3. Brunelli B, Gorson KC. The use of complementary and alternative medicines by patients with peripheral neuropathy. J Neurol Sci. 2004;218(1):59-66.

4. Russo A, Borrelli F. Bacopa monniera, a reputed nootropic plant: an overview. Phytomedicine. 2005;12(4):305-17.

5. Das A, Shanker G, Nath C, Pal R, Singh S, Singh HK. A comparative study in rodents of standardized extracts of Bacopa monniera and Ginkgo biloba: anticholinesterase and cognitive enhancing activities. Pharmacol Biochem Be. 2002;73(4):893-900.

6. Kamkaew N, Norman Scholfield C, Ingkaninan K, Taepavarapruk N, Chootip K. Bacopa monnieri Increases cerebral blood flow in rat independent of blood pressure. Phytother Res. 2012;27(1):135-8.

7. Charles PD, Ambigapathy G, Geraldine P, Akbarsha MA, Rajan KE. Bacopa monniera leaf extract up-regulates tryptophan hydroxylase (TPH2) and serotonin transporter (SERT) expression: implications in memory formation. J Ethnopharmacol. 2011:134(1):55-61.

8. Sairam K, Dorababu M, Goel R, Bhattacharya S. Antidepressant activity of standardized extract of Bacopa monniera in experimental models of depression in rats. Phytomedicine. 2002;9(3):207-11.

9. Bhattacharya S, Ghosal S. Anxiolytic activity of a standardized extract of Bacopa monniera: an experimental study. Phytomedicine. 1998;5(2):77-82.

10. Mathew J, Paul J, Nandhu M, Paulose C. Bacopa monnieri And Bacoside-a for ameliorating epilepsy associated behavioral deficits. Fitoterapia. 2010;81(5):315-22.

11. Mathew J, Gangadharan G, Kuruvilla KP, Paulose C. Behavioral deficit and decreased GABA receptor functional regulation in the hippocampus of epileptic rats: effect of Bacopa monnieri. Neurochem Res. 2011;36(1):7-16.

12. Krishnakumar A, Abraham PM, Paul J, Paulose C. Down-regulation of cerebellar $5-\mathrm{HT}_{2}$ receptors in pilocarpine-induced epilepsy in rats: therapeutic role of Bacopa monnieri extract. J Neurol Sci. 2009;284(1):124-8.

13. Jadiya P, Khan A, Sammi SR, Kaur S, Mir SS, Nazir A. Anti-parkinsonian effects of Bacopa monnieri: insights from transgenic and pharmacological Caenorhabditis elegans models of Parkinson's disease. Biochem Biophys Res Commun. 2011:413(4):605-10

14. Singh M, Murthy $V$, Ramassamy C. Standardized extracts of Bacopa monniera protect against MPP+-and paraquat induced toxicity by modulating mitochondrial activities, proteasomal functions, and redox pathways. Toxicol Sci. 2012;125(1):219-32.

15. Anand A, Saraf MK, Prabhakar S. Antiamnesic effect of B. monniera on L-NNA induced amnesia involves calmodulin. Neurochem Res. 2010;35(8):1172-81.

16. Prabhakar S, Saraf MK, Banik A, Anand A. Bacopa monniera selectively attenuates suppressed superoxide dismutase activity in diazepam induced amnesic mice. Ann Neurosci. 2011;18(1):8-13.
17. Saraf MK, Anand A, Prabhakar S. Scopolamine induced amnesia is reversed by Bacopa monniera through participation of kinase-CREB pathway. Neurochem Res. 2010;35(2):279-87.

18. Khan AV, Ahmed QU, Shukla I, Khan AA. Antibacterial efficacy of Bacopa monnieri leaf extracts against pathogenic bacteria. Asian Biomed. 2011:4(4):651-5.

19. Ghosh T, Maity TK, Sengupta P, Dash DK, Bose A. Antidiabetic and in vivo antioxidant activity of ethanolic extract of Bacopa monnieri Linn. Aerial parts: a possible mechanism of action. Iran J Pharm Res. 2010;7(1):61-8.

20. Channa S, Dar A, Anjum S, Yaqoob M. Anti-inflammatory activity of Bacopa monniera in rodents. J Ethnopharmacol. 2006:104(1):286-9.

21. Viji V, Helen A. Inhibition of lipoxygenases and cyclooxygenase-2 enzymes by extracts isolated from Bacopa monniera (L.) Wettst. J Ethnopharmacol. 2008;118(2):305-11.

22. Viji V, Helen A. Inhibition of pro-inflammatory mediators: role of Bacopo monniera (L.) Wettst. Inflammopharmacology. 2011;19(5):283-91.

23. Viji V, Kavitha S, Helen A. Bacopa monniera (L.) wettst inhibits type ii collagen-induced arthritis in rats. Phytother Res. 2010;24(9):1377-83.

24. Kamkaew N, Scholfield CN, Ingkaninan K, Maneesai P, Parkington HC, Tare $\mathrm{M}$, et al. Bacopa monnieri And its constituents is hypotensive in anaesthetised rats and vasodilator in various artery types. J Ethnopharmacol. 2011;137:790-5.

25. Janani P, Sivakumari K, Geetha A, Yuvaraj S, Parthasarathy C. Bacoside a downregulates matrix metalloproteinases 2 and 9 in DEN-induced hepatocellular carcinoma. Cell Biochem Funct. 2010;28(2):164-9.

26. Dar A, Channa S. Relaxant effect of ethanol extract of Bacopa monniera on trachea, pulmonary artery and aorta from rabbit and guinea pig. Phytother Res. 1997:11(4):323-5.

27. Dar A, Channa S. Calcium antagonistic activity of Bacopa monniera on vascular and intestinal smooth muscles of rabbit and guinea-pig. J Ethnopharmacol. 1999;66(2):167-74

28. Sairam K, Rao CV, Babu MD, Goel R. Prophylactic and curative effects of Bacopa monniera in gastric ulcer models. Phytomedicine. 2001;8(6):423-30

29. Goel R, Sairam K, Dora Babu M, Tavares I, Raman A. In vitro evaluation of Bacopa monniera on anti-helicobacter pylori activity and accumulation of prostaglandins. Phytomedicine. 2003:10(6):523-7.

30. Bhaskar M, Jagtap A. Exploring the possible mechanisms of action behind the antinociceptive activity of Bacopa monniera. Int J Ayurveda Res. 2011;2(1):2-7.

31. Abbas M, Subhan F, Mohani N, Rauf K, Ali G, Khan M. The involvement of opioidergic mechanisms in the activity of Bacopa monnieri extract and its toxicological studies. Afr J Pharm Pharmacol. 2011;5(8):1120-4.

32. Behera P, Sahoo P, Pradhan D. Neuroprotective effect of Bacopa monnieri leaf extract targeted at adenosine receptor in diabetic neuropathic pain. J Pharm Res. 2010:3(8):1806-9.

33. Kalamade V, Pillai M, Kalamade I. Effect of Bacopa monniera (Linn.) on lipid peroxidation and lipofuscinogenesis in prostate gland of D-galactose induced aging mice, Mus musculus. Indian J Exp Biol. 2008;46(7):547-9.

34. Chaudhuri P, Srivastava R, Kumar S. Phytotoxic and antimicrobial constituents of Bacopa monnieri and Holmskioldia sanguinea. Phytother Res. 2004;18(2):114-7.

35. Shinomol GK, Bharath MMS. Pretreatment with Bacopa monnieri extract offsets 3-nitropropionic acid induced mitochondrial oxidative stress and dysfunctions in the striatum of prepubertal mouse brain. Can J Physiol Pharmacol. 2012;90(5):595-606.

36. Garg A, Kumar A, Nair AGC, Reddy AVR. Elemental analysis of brahmi (Bacopa monnieri) extracts by neutron activation and its bioassay for antioxidant, radio protective and anti-lipid peroxidation activity. J Radioanal Nucl Chem. 2009;281(1):53-8.

37. Russo A, Izzo AA, Borrelli F, Renis M, Vanella A. Free radical scavenging capacity and protective effect of Bacopa monniera L. on DNA damage. Phytother Res. 2003;17(8):870-5.

38. Sheikh N, Ahmad A, Siripurapu KB, Kuchibhotla VK, Singh S, Palit G. Effect of Bacopa monniera on stress induced changes in plasma corticosterone and brain monoamines in rats. J Ethnopharmacol. 2007:111(3):671-6.

39. Rai D, Bhatia G, Palit G, Pal R, Singh S, Singh HK. Adaptogenic effect of Bacopa monniera (Brahmi). Pharmacol Biochem Be 2003:75(4):823-30.

40. Rauf K, Subhan F, Sewell RDE. A bacoside containing Bacopa monnieri extract reduces both morphine hyperactivity plus the elevated striatal dopamine and serotonin turnover. Phytother Res. 2011;26(5):758-63. 
41. Sumathi T, Veluchamy G. Inhibitory effect of Bacopa monniera on morphine induced pharmacological effects in mice. Nat Prod Sci. 2007;13(1):46-53.

42. Shahid M, Subhan F, Ullah I, Ali G, Alam J, Shah R. Beneficial effects of Bacopa monnieri extract on opioid induced toxicity. Heliyon. 2016;2(2):e00068.

43. Hosamani R. Neuroprotective efficacy of Bacopa monnieri against rotenone induced oxidative stress and neurotoxicity in Drosophila melanogaster. Neurotoxicology. 2009;30(6):977-85.

44. Anbarasi K, Kathirvel G, Vani G, Jayaraman G, Shyamala DC. Cigarette smoking induces heat shock protein $70 \mathrm{kDa}$ expression and apoptosis in rat brain: modulation by bacoside a. Neuroscience. 2006;138(4):1127-35.

45. Limpeanchob N, Jaipan S, Rattanakaruna S, Phrompittayarat W, Ingkaninan K. Neuroprotective effect of Bacopa monnieri on beta-amyloid-induced cell death in primary cortical culture. J Ethnopharmacol. 2008;120(1):112-7.

46. Ullah I, Subhan F, Rudd JA, Rauf K, Alam J, Shahid M, et al. Attenuation of cisplatin-induced emetogenesis by standardized Bacopa monnieri extracts in the pigeon: behavioral and neurochemical correlations. Planta Med. 2014;80(17):1569-79.

47. Alam J, Subhan F, Ullah I, Shahid M, Ali G, Sewell RD. Synthetic and natura antioxidants attenuate cisplatin-induced vomiting. BMC Pharmacol Toxicol. 2017;18(1):4.

48. Mohanty IR, Maheswari U, Joseph D, Moghe V. Bacopa monniera augments endogenous antioxidants and attenuates myocardial injury. Int J Integr Biol. 2009:7(2):73-9.

49. Mohanty IR, Maheshwari U, Joseph D, Deshmukh Y. Bacopa monniera protects rat heart against ischaemia-reperfusion injury: role of key apoptotic regulatory proteins and enzymes. J Pharm Pharmacol. 2010;62(9):1175-84.

50. Janani $P$, Sivakumari K, Parthasarathy C. Hepatoprotective activity of bacoside a against $\mathrm{N}$-nitrosodiethylamine-induced liver toxicity in adult rats. Cell Biol Toxicol. 2009;25(5):425-34.

51. Sumathi T, Nongbri A. Hepatoprotective effect of Bacoside-a, a major constituent of Bacopa monniera Linn. Phytomedicine. 2008;15(10):901-5.

52. Sumathy T, Subramanian S, Govindasamy S, Balakrishna K, Veluchamy G. Protective role of Bacopa monniera on morphine induced hepatotoxicity in rats. Phytother Res. 2001;15(7):643-5.

53. Shahid M, Subhan F. Protective effect of Bacopa monniera methanol extract against carbon tetrachloride induced hepatotoxicity and nephrotoxicity. Pharmacologyonline. 2014;2(2):18-28.

54. Sumathi T, Devaraj S. Effect of Bacopa monniera on liver and kidney toxicity in chronic use of opioids. Phytomedicine. 2009;16(10):897-903.

55. Downey LA, Kean J, Nemeh F, Lau A, Poll A, Gregory R, et al. An acute, double-blind, placebo-controlled crossover study of $320 \mathrm{mg}$ and $640 \mathrm{mg}$ doses of a special extract of Bacopa monnieri (CDRI 08) on sustained cognitive performance. Phytother Res. 2013;27(9):1407-13.

56. Benson S, Downey LA, Stough C, Wetherell M, Zangara A, Scholey A. An acute, double-blind, placebo-controlled cross-over study of $320 \mathrm{mg}$ and 640 mg doses of Bacopa monnieri (CDRI 08) on multitasking stress reactivity and mood. Phytother Res. 2014;28(4):551-9.

57. Nathan PJ, Clarke J, Lloyd J, Hutchison C, Downey L, Stough C. The acute effects of an extract of Bacopa monniera (Brahmi) on cognitive function in healthy normal subjects. Hum Psychopharmacol Clin Exp. 2001;16(4):345-51.

58. Stough C, Lloyd J, Clarke J, Downey L, Hutchison C, Rodgers T, et al. The chronic effects of an extract of Bacopa monniera (Brahmi) on cognitive function in healthy human subjects. Psychopharmacology. 2001;156(4):481-4.

59. Raghav S, Singh H, Dalal P, Srivastava J, Asthana O. Randomized controlled trial of standardized Bacopa monniera extract in age-associated memory impairment. Indian J Psychiatry. 2006;48(4):238-42.

60. Morgan A, Stevens J. Does Bacopa monnieri improve memory performance in older persons? Results of a randomized, placebo-controlled, double-blind trial. J Altern Complement Med. 2010;16(7):753-9.

61. Calabrese C, Gregory WL, Leo M, Kraemer D, Bone K, Oken B. Effects of a standardized Bacopa monnieri extract on cognitive performance, anxiety, and depression in the elderly: a randomized, double-blind, placebocontrolled trial. J Altern Complement Med. 2008;14(6):707-13.

62. Goswami S, Saoji A, Kumar N, Thawani V, Tiwari M, Thawani M. Effect of Bacopa monnieri on cognitive functions in Alzheimer's disease patients. Int J Collaborat Res Int Med Public Health. 2011;3:285-93.

63. Murthy PBS, Raju VR, Ramakrisana T, Chakravarthy MS, Kumar KV Kannababu S, et al. Estimation of twelve bacopa saponins in Bacopa monnieri extracts and formulations by high-performance liquid chromatography. Chem Pharm Bull (Tokyo). 2006;54(6):907-11.
64. Deepak M, Sangli G, Arun P, Amit A. Quantitative determination of the major saponin mixture bacoside a in Bacopa monnieri by HPLC. Phytochem Anal. 2005;16(1):24-9.

65. Deepak M, Amit A. 'Bacoside B' - the need remains for establishing identity. Fitoterapia. 2013;87(2013):7-10.

66. Rauf K, Subhan F, Abbas M, Badshah A, Ullah I, Ullah S. Effect of bacopasides on acquisition and expression of morphine tolerance. Phytomedicine. 2011;18:836-42

67. Rauf K, Subhan F, Al-Othman A, Khan I, Zarrelli A, Shah M. Preclinical profile of bacopasides from Bacopa monnieri (BM) as an emerging class of therapeutics for management of chronic pains. Curr Med Chem. 2013;20(8):1028-37.

68. Sahoo PK, Pradhan D, Behera P. Neuroprotective effect of Bacopa monnieri leaf extract targeted at adenosine receptor in diabetic neuropathic pain. J Pharm Res. 2010:3(8):1806-9.

69. Bennett GJ, Xie Y-K. A peripheral mononeuropathy in rat that produces disorders of pain sensation like those seen in man. Pain. 1988:33(1):87-107.

70. Shahid M, Subhan F, Ahmad N, Ali G, Akbar S, Fawad K, et al. Topical gabapentin gel alleviates allodynia and hyperalgesia in the chronic sciatic nerve constriction injury neuropathic pain model. Eur J Pain. 2017:21(4):668-80.

71. Vollala VR, Upadhya S, Nayak S. Enhanced dendritic arborization of amygdala neurons during growth spurt periods in rats orally intubated with Bacopa monniera extract. Anat Sci Int. 2011;86(4):179-88.

72. Vollala VR, Upadhya S, Nayak S. Enhanced dendritic arborization of hippocampal CA3 neurons by Bacopa monniera extract treatment in adult rats. Romanian J Morphol Embryol. 2011;52(3):879-86.

73. Ali G, Subhan F, Abbas M, Zeb J, Shahid M, Sewell RD. A streptozotocininduced diabetic neuropathic pain model for static or dynamic mechanical allodynia and vulvodynia: validation using topical and systemic gabapentin. Naunyn Schmiedeberg's Arch Pharmacol. 2015;388:1129-40.

74. Chaplan S, Bach F, Pogrel J, Chung J, Yaksh T. Quantitative assessment of tactile allodynia in the rat paw. J Neurosci Methods. 1994;53(1):55-63.

75. Nakazato-Imasato E, Tanimoto-Mori S, Kurebayashi Y. Effect of mexiletine on dynamic allodynia induced by chronic constriction injury of the sciatic nerve in rats. J Vet Med Sci. 2009:71(7):991-4.

76. Bennett GJ, Chung JM, Seltzer Ze. Models of neuropathic pain in the rat. Curr Protoc Pharmacol. 2003: Chapter 5:Unit5.32. doi: 10.1002/0471141755. ph0532s21

77. Decosterd I, Woolf CJ. Spared nerve injury: an animal model of persistent peripheral neuropathic pain. Pain. 2000;87(2):149-58.

78. Kim KJ, Chung JM. Comparison of three rodent neuropathic pain models. Exp Brain Res. 1997:113(2):200-6.

79. Austin PJ, Wu A, Moalem-Taylor G. Chronic constriction of the sciatic nerve and pain hypersensitivity testing in rats. J Vis Exp. 2012;Mar 13 (61):e3393. doi:10.3791/3393.

80. Subhan F, Abbas M, Rauf K, Baseer A. Anti GIT motility, toxicological and phytochemical studies on Bacopa monnieri. Pharmacologyonline. 2010;3:937-50.

81. Jyoti A, Sethi P, Sharma D. Bacopa monniera prevents from aluminium neurotoxicity in the cerebral cortex of rat brain. J Ethnopharmacol 2007;111(1):56-62.

82. Hazra S, Banerjee R, Das BK, Ghosh AK, Banerjee TK, Hazra US, et al. Evaluation of antidepressant activity of Bacopa monnieri in rat: a study in animal model of depression. Drug Discov. 2012;2:8-13.

83. Nicholson B, Verma S. Comorbidities in chronic neuropathic pain. Pain Med. 2004:5(s1):S9-S27.

84. Sandkühler J. Models and mechanisms of hyperalgesia and allodynia. Physiol Rev. 2009;89(2):707-58.

85. Sharma S, Kulkarni SK, Agrewala JN, Chopra K. Curcumin attenuates thermal hyperalgesia in a diabetic mouse model of neuropathic pain. Eur J Pharmacol. 2006;536(3):256-61.

86. Gilron I, Bailey JM, Tu D, Holden RR, Weaver DF, Houlden RL. Morphine, gabapentin, or their combination for neuropathic pain. $\mathrm{N}$ Engl J Med. 2005;352(13):1324-34

87. Wallin J, Cui JG, Yakhnitsa V, Schechtmann G, Meyerson BA, Linderoth B. Gabapentin and pregabalin suppress tactile allodynia and potentiate spinal cord stimulation in a model of neuropathy. Eur J Pain. 2002;6(4):261-72.

88. Subhan F, Abbas M, Rauf K, Arfan M, Sewell RD, Ali G. The role of opioidergic mechanism in the activity of Bacopa monnieri extract against tonic and acute phasic pain modalities. Pharmacologyonline. 2010;3:903-14. 
89. Le Bars D, Gozariu M, Cadden SW. Animal models of nociception. Pharmacol Rev. 2001;53(4):597-652.

90. Plone MA, Emerich DF, Lindner MD. Individual differences in the hotplate test and effects of habituation on sensitivity to morphine. Pain. 1996;66(2):265-70.

91. Malmberg AB, Bannon AW. Models of nociception: hot-plate, tail-flick, and formalin tests in rodents. Current protocols in neuroscience. 1999:Chapter 8:Unit 9. doi: 10.1002/0471142301.ns0809s41.

92. Bansal M, Kumar A, Reddy MS. Diversity among wild accessions of Bacopa monnieri (L.) Wettst. And their morphogenetic potential. Acta Physiol Plant. 2014;36(5):1177-86.

93. Rose M, Kam P. Gabapentin: pharmacology and its use in pain management. Anaesthesia. 2002;57(5):451-62.

94. Bennett MI, Simpson KH. Gabapentin in the treatment of neuropathic pain. Palliat Med. 2004:18(1):5-11.

95. Gilron I, Flatters SJ. Gabapentin and pregabalin for the treatment of neuropathic pain: A review of laboratory and clinical evidence. Pain Res Manag. 2006;11(Suppl A):16A-29A.

96. Cohen S, Mao J. Neuropathic pain: mechanisms and their clinical implications. Br Med J. 2014;348:f7656.

97. Preethi J, Singh HK, Charles PD, Rajan KE. Participation of microRNA 124-CREB pathway: a parallel memory enhancing mechanism of standardised extract of Bacopa monniera (BESEB CDRI-08). Neurochem Res. 2012;37(10):2167-77.

98. Piyabhan P, Wetchateng T. EPA-0094-cognitive enhancement effect of Bacopa monnieri on vesicular glutamate transporter 2, vglut2, in the prefrontal cortex, striatum and hippocampus of schizophrenia rat model. Eur Psychiatry. 2014;29(1):1.

99. Piyabhan P, Wetchateng T. Neuroprotective effects of Bacopa monnieri (Brahmi) on novel object recognition and NMDAR1 immunodensity in the prefrontal cortex, striatum and hippocampus of sub-chronic phencyclidine rat model of schizophrenia. J Med Assoc Thail. 2014;97(8):S50-5.

100. Aman U, Subhan F, Shahid M, Akbar S, Ahmad N, Ali G, et al. Passiflora incarnata Attenuation of neuropathic allodynia and vulvodynia apropos GABA-ergic and opioidergic antinociceptive and behavioural mechanisms. BMC Complement Altern Med. 2016;16:77.

101. Muthuraman A, Singh N. Attenuating effect of Acorus calamus extract in chronic constriction injury induced neuropathic pain in rats: an evidence of anti-oxidative, anti-inflammatory, neuroprotective and calcium inhibitory effects. BMC Complement Altern Med. 2011;11:24.

102. Raafat K, El-Lakany A. Acute and subchronic in-vivo effects of Ferula hermonis $L$ and Sambucus nigra $L$ and their potential active isolates in a diabetic mouse model of neuropathic pain. BMC Complement Altern Med. 2015;15:257.

103. Garg G, Adams JD. Treatment of neuropathic pain with plant medicines. Chin J Integr Med. 2012;18(8):565-70.

104. Fleming S, Rabago DP, Mundt MP, Fleming MF. CAM therapies among primary care patients using opioid therapy for chronic pain. BMC Complement Altern Med. 2007;7:15.

105. Sherman KJ, Cherkin DC, Connelly MT, Erro J, Savetsky JB, Davis RB, et al. Complementary and alternative medical therapies for chronic low back pain: what treatments are patients willing to try? BMC Complement Altern Med. 2004:4:9.

\section{Submit your next manuscript to BioMed Central and we will help you at every step:}

- We accept pre-submission inquiries

- Our selector tool helps you to find the most relevant journal

- We provide round the clock customer support

- Convenient online submission

- Thorough peer review

- Inclusion in PubMed and all major indexing services

- Maximum visibility for your research

Submit your manuscript at www.biomedcentral.com/submit 